\title{
ISS 1018 CpG Oligodeoxynucleotide
}

National Cancer Institute

\section{Source}

National Cancer Institute. ISS 1018 CpG Oligodeoxynucleotide. NCI Thesaurus. Code C61080.

A short, synthetic, unmethylated CpG motif-based oligodeoxynucleotide (CpG ODN) with immunostimulatory activity. As an immunostimulatory sequence (ISS) that signals through Toll-like receptor 9 (TLR9), ISS 1018 CpG ODN induces the production of immunog lobulin by B cells and interferon (IFN) -alpha, IFN-beta, interleukin (IL) -12, and tumor necrosis factor (TNF) -alpha by plasmacytoid dendritic cells (pDC). pDC, through cell-cell contact, and IFN-alpha and -beta, in turn, induce natural killer (NK) cell proliferation, NK cell production of IFN-gamma, and NK cell-mediated cytotoxicity; secreted IFNs also stimulate bystander T cell activation and differentiation of naive CD4+ T cells into T-helper 1 cells on specific antigen challenge. In addition, ISS 1018 CpG ODN promotes antigen presentation and co-stimulatory molecule expression. 